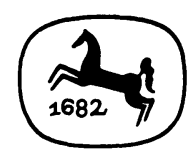

\title{
Literatur im Prozeß \\ der Zivilisation
}

»Die Definition dessen, was Kunst sei, ist allemal von dem vorgezeichnet, was sie einmal war, legitimiert sich aber nur an dem, wozu sie geworden ist, offen zu dem, was sie werden will und vielleicht werden kann.«

Th. W. Adorno

»Nur wenn die Wissenschaften die permanente Erweiterung der technischen Verfügungsgewalt gleichzeitig im Horizont der praktischen Folgen, angesichts deren wir handeln müssen, und das heißt auch: aus historischen Voraussetzungen reflektieren lernen, werden sie die Kraft zur akademischen Bildung in einem sozial gewandelten Sinn zurückgewinnen.«

J. Habermas 
Reiner Wild

\section{Literatur im Prozeß der Zivilisation}

Entwurf einer theoretischen Grundlegung der Literaturwissenschaft

Erschienen im dreihundertsten Jahr der J. B. Metzlerschen Verlagsbuchhandlung Stuttgart 
CIP-Kurztitelaufnahme der Deutschen Bibliothek

Wild, Reiner:

Literatur im Prozeß der Zivilisation: Entwurf

e. theoret. Grundlegung d. Literaturwiss. /

Reiner Wild. - Stuttgart: Metzler, 1982.

ISBN 978-3-476-00523-6

ISBN 978-3-476-03170-9 (eBook)

DOI $10.1007 / 978-3-476-03170-9$

(C) 1982 Springer-Verlag GmbH Deutschland Ursprünglich erschienen bei J.B. Metzlersche Verlagsbuchhandlung und Carl Emst Poeschel Verlag GmbH in Stuttgart 1982 
Für Inge

ohne die es nicht wäre was es ist 


\section{Inhalt}

Einleitung: Versuch einer Diagnose $\ldots \ldots \ldots \ldots \ldots \ldots \ldots \ldots \ldots . \quad 1$

Bemerkungen über die Krise der Wissenschaften $\ldots \ldots \ldots \ldots \ldots 1$

Bemerkungen über den Begriff der Ästhetik ............. 5

Bemerkungen über den Begriff der Geschichte ........... 11

»Literatur im Prozeß der Zivilisation « ................. 19

Erster Teil: Literaturwissenschaft und Geschichte

Versuch einer Bestimmung ihres Verhältnisses

1 System der Wissenschaften und Sinnkonstitution ........... 25

2 Literaturwissenschaft als historisch-hermeneutische

Wissenschaft .......................... 31

3 Geistesgeschichtliche und sozialgeschichtliche Konzeptionen ... 37

4 Literatur als Mimesis ........................... 43

5 Theorie der Geschichte ....................... 50

Zweiter Teil: Literatur im Prozeß der Zivilisation

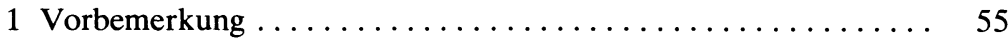

2 Die Theorie der Zivilisation von Elias. Eine Skizze . . . . . . . . . 57

3 Zwischenbemerkung zum Begriff der Funktion ............ 69

4 Der dokumentarische Charakter der Literatur .............. 73

5 Die didaktische Funktion der Literatur .............. 75

6 Dominante, residuale und progredierende Verhaltensstandards; dominante, residuale und progredierende literarische Formen ... 79

7 Die gesellige und die sensibilisierende Funktion der Literatur ... 90

8 Die entlastende Funktion der Literatur ................ 102

9 Die erfahrungserweiternde Funktion der Literatur ......... 110

10 Die kritische Funktion der Literatur ............... 118

11 Die utopische Qualität und die antizipierende Funktion der Literatur . . . . . . . . . . . . . . . . . . . . . . . . . . 127

12 Zusammenfassung der Funktionen $\ldots \ldots \ldots \ldots \ldots \ldots \ldots \ldots$ 
VIII Inhalt

13 Freude an der Literatur . . . . . . . . . . . . . . 141

14 Aisthesis oder die Wahrnehmungsleistung der Literatur . . . . . 152

1 Die Veränderung der Sichtweisen ............... 152

2 Eduard Mörike: s.pember-Morgen $\ldots \ldots \ldots \ldots \ldots \ldots \ldots 1$

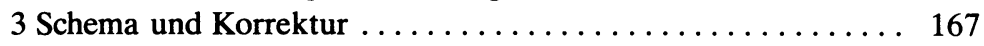

15 Erinnerung und Identität. Konstitution von Sinn . . . . . . . . 180

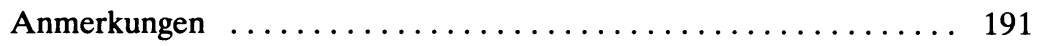

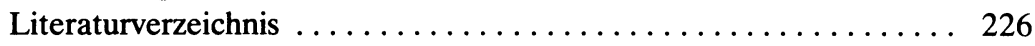

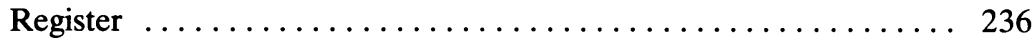

